\title{
Last but not least
}

\author{
Anthony L. Estrera, MD
}

See related article on pages $144-54$ in the January 2015 issue.

The "endovascular revolution" began as a result of the pioneering works of Parodi and colleagues ${ }^{1}$ (endovascular abdominal aortic aneurysm repair) and Dake and colleagues $^{2}$ (thoracic endovascular aneurysm repair). For the past 20 years, this revolution has expanded as advancements in endovascular technologies have allowed applicability to most aortic pathologies. Most recently, whether via hybrid approach or complete endovascular exclusion with fenestrated or branched techniques, the transverse arch and thoracoabdominal aorta also have been tackled. Although endovascular exclusion of the transverse arch and thoracoabdominal aorta remains far from perfect, these aortic locations are being treated with increasing frequency. Only the ascending aorta and the aortic root remain.

In one of the larger series to date, Roselli and colleagues ${ }^{3}$ reported their experience with stent grafting the ascending aorta in "high-risk" patients. In all, 22 patients with varying diseases, including acute type A aortic dissection, intramural hematoma (IMH), pseudoaneurysm, and chronic dissection, were treated. Early results were acceptable, with a $14 \%$ early mortality and a $14 \%$ incidence of stroke. In follow-up (mean, 12 months), 3 late deaths occurred, all apparently unrelated to aortic pathology, with 6 reinterventions $(32 \%)$ in the 19 survivors. Planned reoperations, as bridge procedures, were performed in 4 of these 6 patients. Thus, only $32 \%$ of patients had initial technical success. After secondary interventions, the successful exclusion was observed in $72 \%$ of patients during initial follow-up.

Although the clinical outcomes of this study were important, the value of this report was the lessons learned from the failures. The authors classified the failures into 3 categories: access related, device related, and patient factors. By acknowledging that 7 patients had more than 1 failure, 6 of the 22 "failures" were attributed to the patient,

\footnotetext{
From the Department of Cardiothoracic and Vascular Surgery, The University of Texas Medical School at Houston, Memorial Hermann Heart \& Vascular Institute, Houston, Tex.

Disclosures: Author has nothing to disclose with regard to commercial support.

Received for publication May 13, 2015; accepted for publication May 14, 2015; available ahead of print June 11, 2015.

Address for reprints: Anthony L. Estrera, MD, Department of Cardiothoracic and Vascular Surgery, The University of Texas Medical School at Houston, 6400 Fannin

St, Suite 2850, Houston, TX 77030 (E-mail: Anthony.L.Estrera@uth.tmc.edu).

J Thorac Cardiovasc Surg 2015;150:771-2

$0022-5223 / \$ 36.00$

Copyright (c) 2015 by The American Association for Thoracic Surgery

http://dx.doi.org/10.1016/j.jtcvs.2015.05.045
}

leaving 16 due to the device or access. The fact that the majority of "failures" were inherently related to the procedure itself underscored the shortfalls of the currently available stent grafts when applied to the proximal aorta. To characterize the failures, the authors provided detailed radiographic information on specific dimensions related to the ascending aorta and innominate artery, including distances from the coronaries to the innominate artery on both the greater and lesser curves. The patients with acute type A dissection tended to have shorter native coronary ostia to tear distances (mean, $1.8 \mathrm{~cm}$ ) when compared with the pseudoaneurysm and chronic dissection subgroups of $3.8 \mathrm{~cm}$ and $5.1 \mathrm{~cm}$, respectively. In addition, the sinotubular junction of the acute type A dissection subgroup tended to be larger than the IMH and chronic dissection groups, $4.5 \mathrm{~cm}$ versus 3.9 and $3.6 \mathrm{~cm}$, respectively. This information, tear distance, and sinotubular junction diameter, suggested that the landing zones of acute type A aortic dissections were more precarious than the other pathologies. Noteworthy was that all early and late deaths occurred in the acute type A aortic dissection group.

Of note, the authors suggested greater oversizing for the ascending aorta, that is, $20 \%$, as opposed to less than $10 \%$, as would be recommended for acute descending thoracic dissection. This greater oversizing was to address this issue of the distensibility of the ascending aorta and the possibility of late stent graft migration. It was thought that liberal oversizing in the ascending aorta may be acceptable, because the potential for retrograde dissection was lessened with exclusion of the ascending aorta, but the aortic root is still susceptible to retrograde dissection and should not be ignored. Unfortunately, the authors did not provide details on the sizing information of each patient. For acute type A dissection, what was sized: the true lumen, the entire diameter, the largest lumen, and so forth? Did this differ for IMH, chronic dissection, and so forth? This information will be important moving forward.

In the end, Roselli and colleagues ${ }^{3}$ provide an important report on what is the largest series of ascending stent grafts to date. The success in high-risk patients was acceptable, but more valuable was the information gleaned from the "failures." It is information from works such as this that will enable the development of better "ascending aortic-specific stent grafts." Although the ascending aorta may be the last frontier for endovascular exclusion, it is 
far from the least complex when one considers its anatomic and physiologic complexities.

\section{References}

1. Parodi JC, Palmaz JC, Barone HD. Transfemoral intraluminal graft implantation for abdominal aortic aneurysms. Ann Vasc Surg. 1991;5:491-9.
2. Dake MD, Miller DC, Semba CP, Mitchell RS, Walker PJ, Liddell RP. Transluminal placement of endovascular stent-grafts for the treatment of descending thoracic aortic aneurysms. N Engl J Med. 1994;331: 1729-34.

3. Roselli E, Indrees J, Greenberg R, Johnston D, Lytle B. Ascending stent grafting in high-risk patients. J Thorac Cardiovasc Surg. 2015;149: 144-54. 